\title{
COVID-19 Pandemic Waves: 4IR Technology Utilisation in Multi-Sector Economy
}

\author{
Israel Edem Agbehadji ${ }^{1, *}$, Bankole Osita Awuzie ${ }^{2}$ (1) and Alfred Beati Ngowi ${ }^{1}$ \\ 1 Research, Innovation and Engagement, Central University of Technology, Bloemfontein 9301, South Africa; \\ angowi@cut.ac.za \\ 2 Centre for Sustainable Smart Cities 4.0, Faculty of Engineering, Built Environment and Information \\ Technology, Central University of Technology, Bloemfontein 9301, South Africa; bawuzie@cut.ac.za \\ * Correspondence: iagbehadji@cut.ac.za or israeldel2006@gmail.com
}

Citation: Agbehadji, I.E.;

Awuzie, B.O.; Ngowi, A.B. COVID-19 Pandemic Waves: 4IR Technology Utilisation in Multi-Sector Economy. Sustainability 2021, 13, 10168. https:/ / doi.org/10.3390/su131810168

Academic Editor: Barbara Motyl

Received: 21 August 2021

Accepted: 8 September 2021

Published: 10 September 2021

Publisher's Note: MDPI stays neutral with regard to jurisdictional claims in published maps and institutional affiliations.

Copyright: (c) 2021 by the authors. Licensee MDPI, Basel, Switzerland. This article is an open access article distributed under the terms and conditions of the Creative Commons Attribution (CC BY) license (https:/ / creativecommons.org/licenses/by/ $4.0 /)$.

\begin{abstract}
In this paper, we reviewed the Fourth Industrial Revolution (4IR) technologies applied to waves of the coronavirus disease (COVID-19). COVID-19 is an existential threat that has resulted in an unprecedented loss of lives, disruption of flight schedules, shutdown of businesses and much more. Though several researchers have highlighted the enormous benefits of 4IR technologies in containing the COVID-19 pandemic, the recent waves of the pandemic call for a thorough review of these technological interventions. The cyber-physical space has had its share of the COVID-19 pandemic effect, and through this review, we highlight the salient issues to help policy formulation towards managing the impact of subsequent COVID-19 waves within such environments. Hence, the purpose of this paper is to review the application of 4IR technologies during the COVID-19 pandemic waves and to highlight their shortcomings. Recent research articles were sourced from an online repository and thoroughly reviewed to highlight 4IR technology applications, innovations, shortcomings and multi-sector challenges. The outcome of this review indicates that the second wave of the pandemic resulted in a lower proportion of patients requiring invasive mechanical ventilation and a lower rate of thrombotic events. In addition, it was revealed that the delay between ICU admissions and tracheal intubation was longer in the second wave in the health care sector. Again, the review suggests that 4IR technologies have been utilized across all the sectors including education, businesses, society, manufacturing, healthcare, agriculture and mining. Businesses have revised their service delivery models to include 4 IR technologies and avoid physical contacts. In society, digital certificates, among other digital platforms, have been utilized to assist with the movements of persons who have been vaccinated. Manufacturing concerns have also utilized robots in manufacturing to reduce human-to-human physical contact. The mining sector has automated their work processes, utilising smart boots to prevent infection, smart health bands and smart disinfection tunnels or walkthrough sanitization gates in the mining work environment. However, the identified challenges of implementing 4IR technologies include low-skilled workers, data privacy issues, data analysis poverty, data management issues and many more. The boom in 4IR technologies calls for intense legislation on sweeping data privacy for regulated tech companies. These findings hold salient implications for policy formulation towards tackling future pandemic outbreaks.
\end{abstract}

Keywords: digital technologies; coronavirus disease (COVID-19) pandemic wave; 4IR technology utilisation; multi-sector economy

\section{Introduction}

The Coronavirus disease 2019 (COVID-19) pandemic, as a public health issue, has disrupted every aspect of our lives. Businesses, education and social structures have been disrupted leading to economic challenges. Recently, the COVID-19 pandemic has been associated with different forms of "pandemic waves", which are identified by their characteristics [1]. Iftimie, López-Azcona [2] indicated that COVID-19 will not disappear 
in the short or medium term because of these changing characteristics; hence, the vaccination process might linger until a sufficiently high percentage of the population has been vaccinated. Furthermore, in order to prevent and slow down virus transmission rate, one has to be well informed about the COVID-19 virus, the disease it causes and how it spreads [3]. The COVID-19 virus spreads primarily through droplets of saliva or discharge from the nose when an infected person coughs or sneezes, so it is important to practice respiratory etiquette such as "coughing into a flexed elbow" [3]. Being informed about these etiquettes are primary in slowing down the transmission rate. Preventive measures to avoid its spread include social or physical distancing, hand-washing or using alcoholbased hand sanitizer and mask-wearing [4]. In addition, the idea of "lockdown light" and "hard lockdown" (or strict lockdown) are some of the measures taken by governments to minimise human movement and reduce the spread of COVID-19 [5]. However, the sustenance of strict lockdowns for longer periods has dire consequences due to economic, social and psychological reasons. Fortunately, the hard lockdown brought the infection under control with reduced cases whereas the "lockdown light" proved unsuccessful [5]. Unfortunately, people became exhausted with adhering to preventive measures, thereby ushering in the different COVID-19 pandemic waves. In addition, the virus's behaviour has changed, leading to a faster rate of transmission. Currently, the third wave of the pandemic being witnessed overstretched the existing health facilities in terms of human capacity and a lack of space in hospitals as COVID-19 patients are staying longer in health facilities. As such, the stretched hospital staff prioritised people with greater survival chances [6].

COVID-19 facilitated paradigm shifts in work structures and revealed larger dependencies on the human work force and intelligence. The continued waves of COVID-19 infections made countries constantly optimise their policy responses and technology interventions [7]. The COVID-19 pandemic has significantly accelerated the global use of technologies associated with 4IR. For instance, in sub-Saharan Africa, many now see the $4 \mathrm{IR}$ as a strategy for engendering the region's COVID-19 recovery [8]. Recently, it was announced that the African continent was set to receive a total of USD 50 billion in support from the World Bank to invest in digital technologies through the introduction of new digital platforms, digital infrastructure installation, digital skills development and provision of enabling a regulatory environment for COVID-19 recovery [8]. Although the 4IR agenda has been the part of the strategy of most organizations and governments, the COVID-19 pandemic accelerated the pace of its adoption via cyber-physical infrastructures in education, health service, social interactions and environmental monitoring. Thus, the COVID-19 pandemic has revealed how we are dependent socially, economically and politically and "exploded the myth of 4IR" in the short term [6].

Technological initiatives have been deployed in the cyber-physical space in an attempt to reduce the spread of the COVID-19 and monitor public areas and patients, develop new effective vaccines and guarantee the continuity of social activities [9]. Since the outbreak of COVID-19 in March 2020, researchers from different fields have provided a wide range of solutions to contain the pandemic. The enormous amount of research makes it difficult to have a general view of the different applications of such technologies towards the management of COVID-19 and an understanding of how research has either evolved or is evolving [10]. Furthermore, the resurgence of COVID-19 infections has accelerated the need for just-in-time government policy responses. Thus, it is imperative to review the technology-related responses by different sectors such as education, business, social environment, manufacturing, health, mining and agriculture within their cyber-physical space in tackling the COVID-19 pandemic waves and highlight the shortfalls, if any. Therefore, the main purpose of this review is to present the technological interventions to containing the COVID-19 pandemic waves. An exploratory study was conducted on recent and related literature, using online repositories, detailing the application of mainstream emerging technologies associated with the $4 \mathrm{IR}$ and big data during COVID-19 pandemic waves. The lessons learned contribute to policy formulation and the development of sector-specific strategic planning for 4IR technology use. The remaining sections of this 
paper are structured as follows: Section 2 discusses the related work, Section 3 presents the shortcomings of 4IR, while future research direction is presented in Section 4. The paper is concluded in Section 5.

\section{Related Work}

\subsection{Variants of COVID-19 Pandemic Wave}

From a historical perspective, the term "wave" came into use during the 1889-1892 influenza outbreak that badly impacted America and Europe [1]. When cases of the outbreak started rising again after subsiding, the term "second wave" was used to distinguish it from the original outbreak [1]. Although there is no formal definition that exists for "waves" of the pandemic, a wave relates to a rise in the number of COVID-19 cases that has a specific peak and then declines or is also referred to as a surge or outbreak [4].

Specifically, the first wave of a pandemic means that the virus starts spreading among many people each day and then reaching a peak number of daily cases. Mostly, positive case numbers, hospitalizations and deaths peaks [4] are experienced during the first pandemic wave. Afterward, the virus spreads less because more people have observed the preventive measures and learned how to prevent themselves from spreading or becoming infected by the coronavirus. Hence, the transmission rates become lower over that period. Whereas, with the second wave of the pandemic, daily case numbers start to increase again in a manner that is worse than the first wave in terms of daily infections and severe illnesses. Generally, the term "second wave" helps people to distinguish from the first surge in cases. During the second wave of the pandemic, the virus's spread begins with a sustained rise in infections in which infection is diagnosed more easily [4]. It has been indicated that the virus that caused the second wave emanated from three sources: (1) imported cases from abroad; (2) asymptomatic cases-people who carry the virus but cannot be identified "if they do not have the nucleic acid test"; (3) people become infected from the environment [11]. The imported cases are attributed to the movement of people who are not aware that they carry the coronavirus. Thus, the second wave was due to an increase in the number of a susceptible populations due to lifted restrictions [11]. The third wave of the pandemic occurred when a third peak was observed in a population as a result of some socioeconomic factors, causing other people to be infected, thus creating a continuous cycle [4]. Therefore, when there is no effective technological systems or innovation to verify the status of people who had travelled from one place to another, it increases the chances of infection.

Waves occur at different times in different regions and look different in places because of factors including the number of people living close together, whether people have access to running water and medical care and if they can use prevention measures [4]. For one wave of a pandemic to end, the virus must be under control and cases have to fall substantially. In addition, for a second wave to start, there has to be a sustained rise in infections [1]. Each wave has a different feature and can impact different populations, even within the same country, as it depends on if the disease is seasonal or the age of population [4]. Hence different forms of pandemic waves can be identified in numerical order as first, second, etc. The cause of different pandemic waves can be attributed to human behaviour, viral variants and minimal government actions [4]. Coccia [12] analyzed the impact of the COVID-19 pandemic on the health of people by comparing the first and second wave data on fatality rates, admissions to the ICU and hospitalizations of people from Italy. The results showed that the first wave of COVID-19 saw an average fatality rate of $15 \%$, while the second wave of COVID-19 showed an average fatality rate of $2.5 \%$. Admission to the Intensive Care Unit (ICU) showed $68 \%$ in the first wave and $14 \%$ in the second wave [12]. Hospitalization of people for the first wave was $839 \%$ and $156 \%$ in the second wave [12]. Thus, the impact of the first wave on people was more severe than the second wave. In this regard, factors including geographic locations with associated diseases that are seasonal, human behaviour and virus mutation should be taken into consideration by any technology intervention strategy. Contou et al [13] compared patients 
between the first and second wave of the COVID-19 pandemic and revealed that during the second wave, a lower proportion of patients required an "invasive mechanical ventilation" and there was a "lower rate of thrombotic" events. Invasive mechanical ventilation is when airflow is pushed into the patient's lungs to help them breathe [13]. The lower rate could be attributed to fact that healthcare workers were familiar with the characteristics of the coronavirus and could employ the needed approach to help the patient. In addition, there was a "delay between ICU admissions and tracheal intubation", which was longer during the second wave, whereas "ICU mortality" and "duration of ICU" stay did not differ between the two waves of COVID-19.

The aftermath of the first COVID-19 pandemic wave saw different pandemic waves (second and third). Various countries experienced the second and third COVID-19 pandemic waves in different months between 2020 and 2021, with the associated variants of coronavirus [12]. For instance, Europe had to cope with the appearance of the second pandemic wave in September 2020 [14], and there were higher levels of admission to Intensive Care Units and total deaths in the first wave of COVID-19 compared with both the second and third wave of the COVID-19 pandemic [12]. The lessons learned from the application of 4IR technologies during these pandemic waves could help reduce the infection rate in subsequent waves of COVID-19 or any other pandemic.

\subsection{IR Technology Intervention for COVID-19 Pandemic Waves}

The Fourth Industrial Revolution (4IR) presents a unique opportunity to interconnect the cyber-physical space through the fusion of technologies from physical, digital and biological spheres [15]. Generally, the 4IR evolved from the Third Industrial Revolution (3IR) - sometimes called the digital revolution involving the development of computers and Information Technology (IT). However, the 4IR is a new age differentiated by the speed of technological breakthrough, the pervasiveness of scope and the tremendous impact of new systems. The 4IR is an era of automation characterised by several emerging technologies ranging from, among others, Artificial Intelligence (AI), the Internet of Things (IoT), cloud computing, big data, blockchain, 3D printing, biotechnology and robotics. The application of each technology or their combination has created a technological disruption in businesses, education, manufacturing and many other sectors of the economy. Emerging technologies such as Artificial Intelligence focuses on building intelligent systems that can make timely decisions from health-related data. The systems built using AI learn from previous data or the first wave of the COVID-19 pandemic data to predict future occurrences, be it a second pandemic wave or third pandemic wave. Unfortunately, at the start of the COVID-19 pandemic, the lack of adequate data made the AI model unable to learn the behaviour of the coronavirus and how human activities can contribute to the spread of infection. After some time, the AI model based on coronavirus infection helped to study the trends in human movement that contribute to fast infection spread.

The Internet of Things (IoT) refers to the interconnection of devices through the internet [16]. The effect of the IoT on businesses cannot be underestimated because of its role in harnessing data collection from connected devices [16]. The IoT environment is quite complex because of the heterogeneity of devices. Thus, each device has its own energy requirement, design requirement and more. Every organisation has its structure, which means different requirements, hence, different IoT requirements, may be established. For instance, educational institutions, industries, healthcare and manufacturing have created their agenda towards the inclusion of the IoT. Hence, the Industrial Internet of Things (IIoT) [16] is one of such innovative strategies to help create sustainable value creation in the industry using the IoT. The current waves of the COVID-19 pandemic have called for the creation of IoT-based COVID-19 pandemic detection and monitoring devices. This has become necessary because of the increasing need to track human movement and a lack of adherence to the COVID-19 pandemic preventive measures. Again, tracking human movement and the tracing of persons could be facilitated through the interconnectedness of persons with the IoT-enabled device location detection approach. 
Cloud computing is an approach that allows devices to perform edge computation so that the final data is stored on remote data storage, that is, the cloud. One approach to enable the use of the software is the creation of open-source software which are designed to operate in cloud computing and distributed environments to assist in the development of big-data-based solutions [17]. The cloud computing model enables service distribution and access to personal data globally [18]. Although there are issues related to the privacy of personal data in the cloud computing environment, it enables access to data globally and the quick processing of data. In the third COVID-19 pandemic wave, data from the health sector suggests that there is a faster rate of transmission of the coronavirus as the result of the mutation of the coronavirus [19]. As persons who are unaware of carrying the infection move from one geo-location to another, the virus changes its structure. Because the cloud computing environment can store historic data [20], it is easy to perform edge processing or use devices to process big datasets on the COVID-19 pandemic and analyse human movement data and check the COVID-19 status of any person. Indeed, the ubiquity of mobile computing devices presents a unique opportunity [21], however, persons in underdeveloped or developing nations might have a challenge in terms of the affordability of mobile devices. Although the COVID-19 pandemic wave is a health-related issue, it has impacted businesses, education and many more sectors of society. The advantage of the cloud computing model is that it offers infrastructure as a service, software as a service and data storage as a service [22]. This presents an opportunity to make data available to a large number of persons, making it easy to monitor the movement of persons and determine if preventive measures are followed religiously. The Internet of Things (IoT) and cloud computing are "standard-bearers of the current digitization process" experienced in different sectors such as education, health, agriculture and many more, as they support the "connectivity and management of devices" which are used for gathering data, delivery, processing and computation under several architectural underpinnings [23].

Three-dimensional printing is an aspect of the 4IR which focuses on design and manufacturing of customised products from the input of CAD digital file [24]. Blockchain has the characteristics of decentralization, openness, anonymity and non-tamperability [25]. The non-tampering feature of blockchain improves the security of medical data. The smart contract mechanism of the blockchain ensures the privacy and data control rights of users and provides effective access mechanisms and services for users to store and access data in the blockchain [26].

The core concept of big data is the derivation of alternative and efficient computing means to ingest, retrieve, process and visualize large amounts of data [23]. Big data interventions for COVID-19 pandemic waves have been enormous. Big data refers to a large amount of data moving with speed. It can be characterised by volume (huge data), velocity (fast processing speed), variability (diverse type of data), veracity (authenticity of data from sources), value (data providing benefit) and more. Big data technology refers to computer technology that quickly obtains valuable information from various types of data [27]. The bedrock for successful 4IR technology deployment is data availability. Specifically, cyberphysical systems are developed and operated based on data-driven methods interacting with the physical space. As 4IR technology advances, it is important to harness the opportunities of big data sources to create a sustainable cyber-physical system. Big data analytic techniques are very suitable to track and control the global spread of COVID-19. Through big data, contacts of patients can be traced to identify COVID-19 infection hotspots [28]. Big data can be useful for analysing and forecasting the reach and impact of the coronavirus on people. COVID-19 trackers help collect real-time data from data sources around the world to equip research scientists, doctors, epidemiologists and policymakers with the most recent data, which can be very helpful in making better decisions to fight against the coronavirus [24]. Controlling the COVID-19 pandemic waves requires an understanding of the virus characteristics [17]. Big data analytics tools play a vital role in building the knowledge required in making decisions and initiating precautionary measures [17]. The vast amount of data on COVID-19 from varied sources are necessary to control the spread. 
The challenges unleashed by the COVID-19 pandemic are anticipated to have a long-term impact on society. Thus, big data offers the opportunity for governments to monitor and evaluate the impact of their policies almost in real-time, iterating and refining measures adaptively [7].

This section presents 4IR technology interventions implemented during different waves of the COVID-19 pandemic focusing on the sectors of education, business, social, manufacturing, agriculture, mining and health.

\subsubsection{Educational Sector}

The disruption of schooling contributes to the already existing education crisis, with 258 million children out of school before the lockdown [29]. Indeed, the COVID-19 pandemic has had a debilitating impact on schooling. To reduce this impact further, 4IR technology components have been adopted. For instance, using digital technology such as Zoom, Microsoft Teams, Google Meet and others for communication, meetings, teaching and learning are innovations that are essential for post-COVID-19 recovery because of their accessibility [30]. The adoption of these digital technologies was rapid during the COVID-19 pandemic as most educational institutions were under pressure to find ways to complete their academic calendar. Hence, parents, lecturers and students had to self-learn to adopt and use these digital technologies.

The first wave of the COVID-19 pandemic saw more introduction of distance learning programmes [15] globally, thereby reducing the "educational inequalities and restricted access" [29]. Schools and universities may also be forced to investigate digital or remote learning solutions to bridge the digital divide and ensure equal opportunities for everyone [31]. This form of teaching and learning allows students to take their course module from their homes. Institutions of Higher Learning had to create a digital repository of course materials, and examinations were taken online. The digitization of learning materials facilitated learning to a large extent and also avoided physical contact. The good side of using a digital repository is the cost reduction and optimisation of transport logistics of students [15]. Indeed, the learning environment in traditional universities has been transformed during and in the aftermath of the first wave of the COVID-19 pandemic. Currently most educational institutions, because of restrictions, have organized lectures, conferences, workshops, social events and many more via online platforms, which otherwise would not have been utilised. While some educational institutions have offered free access to their online services, others have also monetized their services to generate income. Lecturers have also deployed online study material (video and text form) to students and encouraged more students to like their material and share it to improve their popularity and to show their authority in the knowledge domain. Hence, one of the lessons learned during the first wave of the COVID-19 pandemic is that the digitalisation of knowledge resources of schools and universities opened up opportunities for self-learning on YouTube. However, parents from deprived places in developing countries who are without the skills to use digital platforms were unable to guide their children, hence, creating an issue of "self-directed learning", which is a form of learning by intervention.

The second and third waves of the COVID-19 pandemic witnessed an acceleration of the use of digital technologies, digital repositories, and self-learning. During the second and third waves, students and lecturers were familiar with some digital technologies. Hence, the academic calendar of higher institutions was gradually restored.

During the hard lockdown, the home became a high data generation place. The big data generated have had an important impact on teachers, schools systems, students and educational curricula [32]. Communication devices in homes generated volumes of data, thus making researchers to study the status of devices [32]. Thus, the Internet of Things (IoT) was considerably felt during the first wave of the COVID-19 pandemic. This technological innovation that was deployed in homes aimed to connect the items we use daily to the internet to bring the physical world closer to the digital world. 


\subsubsection{Business Sector Service Delivery}

The COVID-19 pandemic is expected to have lasting impacts on the traditional method of doing business in the post-pandemic era [33]. The COVID-19 pandemic forced organizations to reinvent their business service delivery models in a quest to avoid losses by shifting focus to digital channels or adopting a digital business model [30]. Businesses witnessed accelerated digitalization of business processes or models during the COVID-19 pandemic. Some of these digital and technological innovations have shown positive results during the first, second and third waves of the pandemic. From the perspective of developing countries, although there were digital payment platforms, the use of these platforms was not rapid until the first wave of the pandemic. For instance, mobile money platforms had larger subscription or use for cashless transactions [9]. The development of digital technologies has transformed many traditional face-to-face business services into optional and value-added services that can be experienced either at home or in the office [33]. The COVID-19 pandemic has seen some telecom operators take advantage of 4IR technologies due to massive expansion in mobile technology, to penetrate massively into the mobile money platforms in the country such as Ghana in the sub-Saharan region [8]. In addition, online banking transactions have improved tremendously due to the hard lockdown [8]. Businesses have also deployed digital technologies to deliver their services in homes of clients/customers during the social distancing and lockdown, which led to the e-commerce boom in some countries in Africa [8,34]. Many of these e-commerce platforms have to be sustained now that people have experienced their value and the convenience of online shopping [31]. Religious organizations, with traditional services, have been completely disrupted due to the COVID-19 pandemic, which also led to the transformation of traditional religious services to digital religious services [31]. Though the COVID-19 pandemic has greatly affected the socioeconomic systems of countries, it has improved business service delivery and increased the pace of digital technology adoption globally. For instance, a report launched by Google and the International Finance Corporation indicated that “Africa's digital economy could contribute $\$ 180$ bn to the continent's GDP by 2025, an increase on the $\$ 115$ bn for which it is currently responsible" [8]. Thus, the COVID-19 pandemic has made businesses and organizations to review their service delivery models and attracted investment which has facilitated the pace of digitization. Although there is a difficulty in drawing a thin line on the digital gains in subsequent pandemic waves, the gains must be sustained and managed. Today, data is has become a very valuable resource which facilitated digitization globally [35]. With the huge investments in digitization and the growth of digital platforms, the challenge is ensuring the data remains secure [36].

As the infectious COVID-19 persists, contactless services using advanced technologies are likely to infiltrate people's daily lives [37]. Thus, the pandemic has brought new opportunities for the service industry, as the digitization of operational processes is being expedited [33]. In addition, the online retail industry has experienced an unexpected renaissance because of the rapid spread of "contact-free consumption patterns" [38].

\subsubsection{Movement and Interactions within a Social Environment}

The digitization of government social programs has intensified the engagement with citizenry [30]. During the first wave of the COVID-19 pandemic, countries such as South Africa and many others created digital platforms for social engagements.

Because some restrictions have limited movement and social life, it affected the free movement of people significantly, hence, digital certification documents were developed. Digital documentation of COVID-19 certificates is a type of document used to represent the COVID-19 vaccination status of an individual [39]. The concept of digital documentation of COVID-19 was a mechanism by which a person's COVID-19-related health data can be digitally documented via an electronic certificate [39]. A "digital green certificate" was a framework for issuing, verifying and accepting interoperable health certificates [40] to facilitate movements. The forms of the green certificate are proof of vaccination, COVID-19 test results and/or information that the holder has recovered from being ill with COVID-19 [40]. 
The framework resulted in the European Union's (EU) Digital COVID Certificate to facilitate the safe movement of citizens in the EU during the COVID-19 pandemic [41]. Therefore, member countries within the EU are required to issue this certificate to its member as digital proof that person has been vaccinated or received negative test results or recovered from COVID-19 [41]. The EU COVID-19 vaccine passport/certificate is a single document issued to a traveller in both manual and digital format [42]. There are three types of this passport/certificate, issued to an individual based on their travel history: the vaccination passport, test certificate and recovery certificate of the holder of this passport/certificate [42].

One of the issues associated with the creation of different vaccines for the COVID-19 pandemic is whether the destination country accepts a particular vaccine as valid. A vaccine checker, which is a digital tool, was introduced to help check whether the destination country had approved a vaccine that travellers should be immunized against COVID-19 with [42]. Although 5.2 billion vaccines have been administered worldwide in the last 9 months [43], supply constraints could lead to delays in receiving a vaccine to other countries, as can a lack of the equipment and material needed to produce the COVID-19 vaccine. The COVID-19 Supply Chain System which focused on three main areas, namely, strategy, implementation and moving forward, has helped in creating a distribution system of vaccines [44]. However, COVID-19 vaccine production and distribution also have their own challenges, and it is necessary to expand capacity globally to avoid COVID-19 vaccine marginalization.

The Cyber-Physical System contributes to the introduction of autonomous machines in the transport industry [16]. At the peak of the first wave of the COVID-19 pandemic, there were difficulties in movement around cities and for fear of contamination from taxi drivers, and thus transport service models composed of autonomous vehicles have become more relevant within the physical space [45]. There are concerns that the deployment of the autonomous vehicles during the second and third waves of the COVID-19 pandemic will increase social isolation [15,46]. On the contrary, this would rather result in a social gathering, as people can drive through shopping malls and attend events while in their autonomous vehicles.

The social dynamic structure created by the different waves of the COVID-19 pandemic required people to be screened and COVID-19 pandemic protocols including wearing a mask and many more have to be adhered to when entering any public place [47]. The new normal of wearing of the mask also calls for checking of the quality of the materials used for the mask and the intensification of mask design standards.

AI-based computer vision cameras are being used to assess whether social distancing is being respected in public areas $[9,48]$. In addition, AI-based thermal imaging cameras have been used to scan public spaces and identify potentially sick people in China [48].

People-tracking wristbands have been deployed to monitor COVID-19 patients' movements in countries such as Bulgaria, Bahrain, India, Hong Kong, Belgium and South Korea [9]. Through the wristbands, authorities and monitoring agencies are alerted once a patient moves from their isolation centres or their homes or tries to remove them.

The deployment of the autonomous vehicles constitutes the physical component of 4IR technologies. These technological interventions were experienced during the second and third waves of the COVID-19 pandemic.

\subsubsection{Manufacturing Sector}

Manufacturers are revamping their growth strategies as COVID-19 continues to cause uncertainty [49]. In this regard, manufacturers view maximizing productivity as not enough; instead, they should look to 4IR technologies to increase resilience, sustainability and growth [49]. The physical component of 4IR interventions during the COVID-19 pandemic is the deployment of robots in manufacturing to reduce human-to-human physical contact. Although the use of robots in manufacturing has been in existence for several years, it took on a new dimension in terms of autonomous disinfection robots for effective 
disinfection tasks [30]. This was necessary because of the deadly nature of COVID-19. There have been more manufacturing technologies and job computerisations to sustain production as human lives are lost because of COVID-19 [16]. Although the first wave of the COVID-19 pandemic disrupted the manufacturing sector, the manufacturing sector regained some momentum in second and third pandemic waves upon the introduction of 4IR technologies in manufacturing. The supply and value chain has been tremendous to create distribution channels and just-in-time products for manufacturers and distributors [50], thus resulting in quicker responses to demands for critical medical supplies [9]. Furthermore, 3D printing innovations are utilized during the COVID-19 pandemic to expedite the production of critical medical supplies such as Personal Protective Equipment (PPE) $[30,48]$. The automation of manufacturing technologies and job computerization has dislocated much of the human capital, causing a new reconfiguration. On the other hand, however, the latest technologies will lead to the creation of new jobs, and there will be new production areas.

One of the challenges in the manufacturing sector is the health and safety of workers during the COVID-19 pandemic [35]. Thus, companies implemented the following: social gathering platforms such as Zoom or Skype used to facilitate interaction; enhanced data collection and analytics to encourage social distancing; and cloud computing to ensure systems and data are stored and run offsite and can be accessed online for remote collaboration. In the area of supply chain management, virtual supply chain management systems were implemented to consolidate real-time information to predict future incidents [35]. In addition, 4IR technology is allowing companies to connect their data in new ways for insights into operations and market status. The COVID-19 pandemic forced manufacturing companies to re-evaluate their outdated data integration systems, which led many to transitioning to the use of Enterprise Resource Planning (ERP) systems; Application Programming Interface (API) and data warehousing solutions to link all systems together [35]; new methods of training staff using Augmented Reality (AR) and remote delivery; and the use of industrial AR for remote working increased since start of the pandemic [51]. In manufacturing, improving production cannot be achieved without operations data, which can be unlocked with operational technology that need to work seamlessly with information technology that can process and interpret the data. Thus, IoT devices are required to capture data to ensure operational efficiency.

COVID-19 caused many organizations to halt business altogether to prioritise reduction of downtime in the short-term, applying machine learning technologies to automatically predict looming threats in production [35]. During COVID-19, manufacturing sectors also maintained a qualified and talented workforce, which was prioritised through the implementation of robotics process automation and applying remote training tools (e.g., augmented reality) to continue employee education without requiring in-person contact [35]. The pandemic has been a catalyst for immense change in the manufacturing industry, unexpectedly accelerating companies into the 4IR [35].

\subsubsection{Health Sector}

The COVID-19 pandemic resulted in many doctors practicing the social isolation of infected persons [15]. Normally, doctors will visit their patients in wards to administer treatments, but because of fear of infection, important steps have been taken to deploy physical components of 4IR technologies such as robot doctor to handle COVID-19 pandemic isolated cases. Robotic medical tools have been deployed to automate high-volume tasks of doctors and surgeons in the hospital. This resulted in Artificial Intelligence specialists and medical transcriptionists, the deployment of robots to handle contaminated waste from COVID-19 cases and robot-controlled, non-contact ultraviolet surface disinfection has also been deployed [30] and the left-hand doctor, a general-medicine robot doctor that supports natural language conversations with patients of COVID-19 [27]. These technologies have transformed the health care sector during the different COVID-19 pandemic waves. The digital component of the 4IR that has been experienced during the COVID-19 pandemic is 
the use of supercomputers and algorithms to perform quick possible drug combinations that would otherwise be done by humans [45].

The different waves of the COVID-19 pandemic have started a discussion within the biological space of the 4IR technologies. This discussion is centred on the creation of a "chip" in humans to monitor the persons who have been infected/sick or not. This discussion, which has created much concern, arose because of the need to locate contact of COVID-19 reported cases and determine hotspots of the pandemic. In this regard, cell phone users were tracked, which created privacy concerns, as hackers can take advantage of biological data on the network of telecom operators to perpetuate their nefarious biohacking activities [52]. Another concern is the use of biological data for the marketing of products, and a person could imagine receiving numerous information on the best drug product. In this new era of the $4 \mathrm{IR}$, automation is in our homes, industries and everywhere. Of course, marketing efforts focus on attracting, converting and retaining people, thus, automation attracts people, which increases online information traffic. The Da Vinci surgical robot system is one of the current surgical robots [53], which is capable of taking pictures of the surgical processes via a $3 \mathrm{D}$ vision system and completing some operations that cannot be done manually.

Another biological space of the 4IR technologies is the implantation of "intelligent life" structured in silicon (computer "brain") [15]. The drone technology (that is, Zipline automated drones) was deployed to shuttle medical supplies and samples of suspected COVID-19 patients [54]. Other 4IR interventions include virtual clinics for telemedicine consultations [24]. Drones and robots are deployed to deliver medical supplies to health facilities and medicine and meals to infected COVID-19 patients [48].

Blockchain technology is widely used in electronic medical record management, drug and supply chain management, health data analysis, etc. Blockchain has great potential in ensuring the openness and transparency of pandemic information and the tracking and traceability of pandemic materials.

Wearable devices with biosensors worn on the body and can sense, record, analyse and manage health data with the support of the related applications. Such devices include: smart watches, smart belts, wearable blood glucose monitors and smart pills [27]. These digital tools are all based on real data and use big data technology and complex algorithms to intelligently determine whether the user is a confirmed case or a potential source of infection [55], and use mobile Bluetooth technology for contact tracing [48]. This makes big data applications more useful in tackling the pandemic that currently confronts the world. The application of the Internet of Medical Things (IoMT) or medical care IoT also helps in fighting the pandemic [10].

During the first wave of the COVID-19 pandemic, China deployed 5G technology combined with artificial intelligence, biometrics and thermal imaging technology for quick temperature measurement of large-scale mobile populations in multiple railway stations across the country and can quickly identify the wearing of masks [27]. Facial recognition can also detect suspected cases in time [56].

"WeDoctor" is a medical Internet platform (known as an internet hospital or mobile hospital) that provides "online + offline" medical services. This platform provided services including free virtual consultation, online self-examination, remote consultation and family medical guidance to the public through remote technology during the first COVID-19 pandemic wave [27].

The fact that COVID-19 cases need to be isolated makes the concept of big data analysis more relevant, as it personalized treatment plans according to different patients [57]. Big data technology can analyze personal health, diagnosis, and treatment data, and prevent personal diseases. Big data technology played a great role in the systematic management of hospitals and effectively improved the hospital's medical quality [27]. Secondly, big data technology can provide doctors with accurate and scientific information, thereby assisting doctors in diagnosis and treatment, reducing the rate of misdiagnosis [27]. These digital tools are all based on real data and use big data technology and complex algorithms 
to intelligently determine whether the user is a confirmed case or a potential source of infection.

Big data fusion analysis helps to identify "close contacts" quickly and accurately from massive amounts of data. It can be characterized into: authoritative data, credible models and accurate queries [58].

The big data platform assisted in providing support to health workers to detect any suspected cases to standardise the management of close contacts [59]. Some interventions include the "12306-ticketing platform" which is used to communicate close contacts of confirmed cases on a vehicle with the local governments and COVID-19 prevention and control agencies [27]; the use of cell phone data to track movement; the use of the Health Code (HC) that leverages big data for digital health certificates [27]; the use of mobile technology for data collection and contact tracing; and the use of technologies associated with the 4IR offer efficient and effective ways to cope with the speed, scope, and impact of the COVID-19 pandemic [48].

The development of new drugs and vaccines requires a large amount of data analysis, large-scale literature screening and scientific supercomputing work [27].

Nanotechnologies are applied for rapid diagnostics, therapeutics, surveillance and monitoring, vaccines, and the creation of new forms of personal protective equipment. An example of such development is a nanomaterial-based sanitizer and nanofiber respiratory masks capable of killing a virus rather than just trapping it, protecting the wearer as well as his or her surroundings [48].

The COVID-19 pandemic has caused a lack of Personal Protective Equipment (PPE)Medical Devices in hospitals worldwide [60]. Three-dimensional printing technology has been used in the design and development of ventilator parts during the COVID-19 pandemic. One of the areas for the application of 3D printing is the design and development of the NanoHack 3D mask, which is recyclable and reusable, compared to the widely used surgical masks and N95 respirators which are not reusable or affect the ecosystem [24]. Moreover, 3D printing hastened the printing of medical protective equipment during the COVID-19 pandemic waves, which stabilised the supplies before the COVID-19 pandemic crisis escalated. In addition, 3D visualization systems have been used for infection risk problems in ordinary retinal operation which provides a significant reduction of COVID-19 infection [61].

Cloud computing is very much suitable to track the worldwide spread of the coronavirus and check the COVID-19 pandemic status. However, this aspect of checking the status of persons during the COVID-19 pandemic waves may require standardisation.

Some interventions to disseminate health information on symptoms, prevention and treatment of COVID-19 pandemic to the citizenry in developing nations such as South Africa, Ghana and Nigeria include the use of WhatsApp push notifications [48]. Digital tools implemented during the COVID-19 pandemic included "real-time epidemiological dashboards, interactive maps of case location, mobile apps for tracing patients' contacts and geofencing to monitor quarantine compliance" [62]. Examples of the integration of tools include the linkage of national health and immigration databases to identify high-risk individuals in Taiwan and the use of multiple digital surveillance sources to map patients' movements in South Korea. In addition, challenges in balancing privacy and public good were identified [62]. Although, developing nations are not on the same level technologically as the developed nations (e.g., China) in terms of robots sanitizing hospitals, airports and roads, the developing nations have also utilised technologies in other ways to combat the coronavirus. For instance, home testing kits, temperature measurement devices and 3D printing are some of the technologies [31]. Though the traditional body temperature measurement is time-consuming and has the threat of close contact and can cause a risk of contamination, it also lacks the element of data collection for further analysis [63]. Digitalisation is disruptive and is changing the healthcare landscape from a reactive model to a system that focuses on "predictive, preventative, personalized and participatory care" [31]. 
Through applications of 4IR technologies, various contactless services have been implemented [64]. Generally, contactless service refers to a method of service delivery that involves indirect interactions between people (e.g., person-machine, person-machineperson), instead of the traditional methods that involve direct person-to-person interactions. Ref. [38] defines an untact (contactless) service as a "service that is provided without face-to-face encounters between employees and customers through digital technologies". Contactless services are generally delivered by advanced technologies, such as Artificial Intelligence (AI), the Internet of Things (IoT), Virtual Reality (VR) and/or Augmented Reality (AR), big data and cloud-based platforms [38]. Thus, different types of contactless services, such as Telemedicine, have been developed based on consumers' needs, while providing personalized customer experiences.

\subsubsection{Agriculture}

The agriculture sector has also been affected by the COVID-19 pandemic because most workers had to stay home. The coronavirus pandemic put the global food system through severe stress, disrupting regular supply chains [65]. In lower-income countries, agriculture provides income to "poor households, food to growing urban population, and export earnings" [66]. However, the low usage of modern inputs, lack of secure land tenure, lack of irrigation systems, poor roads resulting in high transportation costs and low public investment in research and development (R\&D) result in limited science-based options [66]. Despite these challenges, the agricultural sector in Northern Africa and South Africa is more "developed, mechanized, productive, and profitable" [66]. Already, the success in mobile technology usage in Africa has brought information to smallholder farmers about when and what to plant based on weather forecasts and technical information about crop varieties, building a knowledge-based agricultural community. Using mobile phones, smallholder farmers can display the price of their farm produce and helped match farmers and wholesalers and reduce transaction costs. Currently, the Africa Development Bank's investments in agriculture is expected to quadruple to about USD 2.4 billion by 2024 to increase productivity in Africa [8]. Several countries across the world are implementing 4IR technologies and digital solutions for smallholder farmers to boost agricultural productivity. Indeed, 4IR technologies played a major role in transforming the food systems [8]. Recently, China launched its "digital village" model to solve the growing food security problem in the drive to overhaul its smallholder farming culture [65]. In addition, internet-enabled devices (such as intelligent sensors), data analysis and fully digital greenhouse automation were employed to revamp the food sector in China. Thus, Chinese farmers in villages have been quick to adopt a digital lifestyle and using mobile payments because the extent to which some areas in the villages are connected to the internet is greater than in large cities [65]. AI, the IoT and big data are the 4IR technologies used for the creation of the "digital village" to ensure food security in China. Blockchain is another popular 4IR technology for smart farming in China-especially relating to the safety of food. Blockchain is used to collect data on the origin, safety and authenticity of food and provide real-time traceability throughout the supply chain [65]. "GoGo" chicken is a blockchain technology for poultry monitoring [65]. Digitizing agriculture requires huge government commitments in network infrastructure in remote areas, for which the "digital village" initiative provides financial and organizational support [65].

Furthermore, 4IR technologies have helped to address Africa's agriculture issues, including land tenure issues, advancing the use of irrigation and reducing water pollution from fertilizer overuse. However, the application is spotty and lacks a supportive policy framework. Likewise, blockchain has been used to create a safe repository for land records and to reduce the transaction costs of land rentals and sales. Uganda is one example that has used blockchain technology for land records. However, a lack of knowledge and understanding of blockchain technology for land issues is one of the challenges. 
Drones are used to spray crops much faster than humans. However, its cost is a deterrent to farmers in low-income countries, hence, government support for producer organizations is much needed [66].

On the contrary, in the developed economies, 4IR technologies are utilised in the agricultural sector in Western Europe, North and South America and East Asia. These technologies are used in a model called "precision agriculture," a method of site-specific crop and farming management used to improve farm profitability, efficiency and sustainability [66]. Indeed, the COVID-19 pandemic brought innovation to Africa's agricultural sector. However, there is a need to quicken the pace of technological inclusion in Africa's farming system. Although some technologies including the use of sensors to monitor weather patterns, blockchain in the land and drones are in use in developing countries, more needs to be done to realise the full potential of 4IR.

\subsubsection{Mining}

The mining industry has also been affected by the pandemic, which resulted in mandatory shutdowns, lower demand for extractive products and slowdowns when managing the risk of infection; these caused loss of production, income and growth [63]. Meanwhile, the COVID-19 pandemic has accelerated the digitization of the work process, as well as the adoption of automation and other innovation tools in the mining industry $[63,67]$. The mining industry visualise the impact of 4IR on its people, processes and technologies. The acceleration of 4IR technologies helps the mining industry to manage the pandemic more effectively [67]. Mining industries would like to boost productivity and find ways to upskill their workforce to work in the new world of Robotic Process Automation in the mining industry and related 4IR technologies [68]. Challenges to be overcome by mining companies in implementing 4IR technologies include data management practices that are not yet mature; the workforce lacks the necessary skills to implement 4IR technologies; and data and cybersecurity concerns [68]. Thus, the ability to manage and use data is a core capability to unlock the value of $4 \mathrm{IR}$. AI-based cameras are a hybrid of thermal, infra-red and visible imaging for predicting and reading real-time body temperature and automatically sending alerts to mine management in case of temperature anomalies. In addition, real-time video analytics can monitor the health and safety parameters in underground and surface mining environments [63]. Other 4IR technologies include smart boots, another digital technology that can be useful to prevent infectious viruses, smart health bands and smart disinfection tunnels or walkthrough sanitization gates [63].

\section{Shortcomings of 4IR Interventions to COVID-19 Pandemic Waves}

In this section, the shortcomings of the Fourth Industrial Revolution (4IR) intervention in different sectors are presented in Table 1 . The shortcomings emanated from the review of literature on 4IR technologies used in education, business, society, manufacturing, health, mining and agriculture to resolve challenges identified in these economic sectors. The 4IR technologies are grouped into physical, digital and biological space.

Table 1. Sectoral shortcomings of 4IR intervention during COVID-19 pandemic waves.

\begin{tabular}{lll}
\hline Sector & \multicolumn{1}{c}{ Sector Challenges } & \multicolumn{1}{c}{ 4IR Technology Application } \\
\hline Education & $\begin{array}{l}\text { Reducing educational inequalities } \\
\text { and restricted access [29] } \\
\text { Avoiding the tradition of } \\
\text { face-to-face learning }\end{array}$ & $\begin{array}{l}\text { Digital space: using digital technology for } \\
\text { communication, meetings, teaching and } \\
\text { learning because of their accessibility [30]; } \\
\text { enabled self-learning using digital } \\
\text { platforms, e.g., YouTube; course material } \\
\text { digitization }\end{array}$ \\
\hline Business & $\begin{array}{l}\text { Traditional face-to-face business } \\
\text { services delivery. } \\
\text { Avoid loss of business service } \\
\text { delivery during the COVID-19 } \\
\text { pandemic }\end{array}$ & $\begin{array}{l}\text { Digital space: The increased pace of use of } \\
\text { digital payment platforms; booming } \\
\text { e-commerce platforms [8] }\end{array}$ \\
\hline
\end{tabular}


Table 1. Cont.

\begin{tabular}{|c|c|c|c|}
\hline Sector & Sector Challenges & 4IR Technology Application & $\begin{array}{c}\text { Shortcomings in Implementing } \\
4 \mathrm{IR}\end{array}$ \\
\hline Social environment & $\begin{array}{l}\text { Movement of people who are not } \\
\text { aware that they carry the } \\
\text { coronavirus } \\
\text { People became exhausted with } \\
\text { adhering to preventive measures }\end{array}$ & $\begin{array}{l}\text { Digital space: Digital documentation of } \\
\text { COVID-19 certificates [39]; creation of } \\
\text { distribution system for COVID-19 } \\
\text { vaccine [44]; people-tracking wristbands } \\
\text { to monitor COVID-19 patients' } \\
\text { movements in countries [9]. } \\
\text { Physical space: AI-based computer vision } \\
\text { cameras to assess social distancing [9,48]; }\end{array}$ & $\begin{array}{l}\text { Low levels of education and } \\
\text { training [69] }\end{array}$ \\
\hline Manufacturing & Health and safety of workers [35] & $\begin{array}{l}\text { use of robots to reduce human to human } \\
\text { physical contacts; autonomous } \\
\text { disinfection robots [30]; production of } \\
\text { critical medical supplies such as Personal } \\
\text { Protective Equipment (PPE) [30,48] } \\
\text { Digital space: use of digital technologies } \\
\text { including Zoom and Skype for interaction } \\
\text { to ensure health and safety of workers and } \\
\text { physical distancing [35]; use of virtual } \\
\text { supply chain management systems to } \\
\text { consolidate real-time information to } \\
\text { predict future incidents [35]. Training staff } \\
\text { using Augmented Reality (AR) and } \\
\text { remote delivery; usage of industrial AR } \\
\text { for remote working [51] }\end{array}$ & $\begin{array}{l}\text { Outdated data integration } \\
\text { systems [35] }\end{array}$ \\
\hline
\end{tabular}

Digital space: Contactless services such as telemedicine services have grown rapidly [33]; use of WhatsApp push notification on health information regarding the symptoms, prevention and treatment of the COVID-19 pandemic [48]; interactive maps of case location; mobile apps for tracing patients' contacts and geofencing to monitor quarantine compliance [62]; digital checking of COVID-19 pandemic status; big data to personalise health, diagnosis and

Social isolation of infected persons [15] Electronic medical record management, drug and supply

Health chain management Ensuring the openness and transparency of pandemic information

Tracking and traceability of pandemic materials

treatment [57]; face recognition can detect suspected cases in time [56]; thermal imaging technology for quick temperature measurement and for identification of wearing of masks [27]; blockchain technology for electronic medical record management and drug supply chain management; IoMT [10]

Physical space: robots sanitizing hospitals, airports and roads in developed nations; NanoHack 3D mask; drones and robots are deployed to deliver medical supplies to health facilities and medicine and meals to infected COVID-19 patients [48]; 3D visualisation system to reduce COVID-19 infection risk of the retinal Biological space: Wearable devices with biosensors worn on the body; implantation of "intelligent life" structured in silicon (computer "brain") [15].

Digital space: land tenure issues, advancing use of irrigation and reducing water pollution from fertilizer overuse with the use of blockchain technology [66]; blockchain to create a safe repository for Agriculture Farm sustainability land records and to reduce the transaction costs of land rentals and sales; high internet availability in farming areas than in large cities [65]; blockchain technology for the data collection on the origin, safety and authenticity of food and to provide
Global healthcare services market expand to other industries [33]; international standardization of contactless healthcare services [33]

Challenges in balancing privacy and public good [62] Biological data hacking [52]
Lack of a supportive policy framework in Africa's digital agriculture system [66] High cost of drones for spraying chemicals on crops and monitoring of farmlands The slow pace of 4IR technologies' 
Table 1. Cont.

\begin{tabular}{|c|c|c|c|}
\hline Sector & Sector Challenges & 4IR Technology Application & $\begin{array}{l}\text { Shortcomings in Implementing } \\
4 \text { IIR }\end{array}$ \\
\hline & & $\begin{array}{l}\text { real-time traceability in the supply chain; } \\
\text { blockchain has been used to create a safe } \\
\text { repository for land records and to reduce } \\
\text { the transaction costs of land rentals and } \\
\text { sales [65] } \\
\text { Physical space: Drones deployed to spray } \\
\text { crops much faster }\end{array}$ & $\begin{array}{l}\text { inclusion in Africa's farming } \\
\text { system }\end{array}$ \\
\hline Mining & $\begin{array}{l}\text { Agility on how to align } \\
\text { technology with mining business } \\
\text { needs to boost productivity and } \\
\text { upskill their workforce to work } \\
\text { lower demand for extractive } \\
\text { products [63] }\end{array}$ & $\begin{array}{l}\text { Digital space: transfer of health } \\
\text { information from physical smart devices } \\
\text { used by miners in real-time to their mobile } \\
\text { device and management authorities for } \\
\text { decision making [63] } \\
\text { Physical space: Robotic Process } \\
\text { Automation; smart boots; smart health } \\
\text { bands; smart disinfection tunnels or } \\
\text { walkthrough sanitization gates [63] }\end{array}$ & $\begin{array}{l}\text { Data management practices are } \\
\text { not yet mature; lack of a skilled } \\
\text { workforce; data and cybersecurity } \\
\text { concerns [68] }\end{array}$ \\
\hline
\end{tabular}

Table 1 presents the shortcoming of the 4IR application to sectors of an economy. These sector categories were impacted by the COVID-19 pandemic waves and a cursory review helped clarify the areas to focus on. The shortcomings of 4IR technologies to fight the waves of the COVID-19 pandemic is that countries vary in terms of capacity on the cyber-physical space and human skills for utilizing these technologies. The threat to digitization is cybersecurity; upskilling workers and young people through the educational systems to new technologies and digitization [69]; broader social, financial investment and international cooperation on policies; and understanding of the social and ethical impacts of emerging technologies, particularly on the young [36]. The cause of different pandemic waves can be attributed to different human behaviour, viral variants and minimal government actions [4]. The imported COVID-19 cases are attributed to the movement of people who are not aware that they carry the coronavirus. The impact of 4IR technologies that were used can be summarised as follows: In education, the second and third waves of the COVID-19 pandemic witnessed an acceleration of the use of digital technologies, digital repository and selflearning; In business, business service delivery models shifted from traditional face-to-face models to massive expansion in mobile technology, and e-commerce boomed during the pandemic; In society, the digital documentation of COVID-19 certificates was used to aid movement; In manufacturing, the use of robots for most manufacturing tasks to reduce human contacts; In health, the use of robots for disinfection of public areas and drones to deliver medical supplies; In Agriculture, the use drones to spray crops; In mining, the use of smart health bands, disinfection tunnels or walkthrough sanitization gates and mobile health alerts are among the 4IR technologies implemented. Increased digitization because of the pandemic has introduced another challenge in terms of managing the disruptive technologies associated with the 4IR [36]. Although digitization resulted in the availability of large volumes of data, there is data analysis poverty created due to lack of technical knowhow to analyse the variety of data and create value from the data. Opportunities that exist in healthcare include promoting education and training for non-face-to-face healthcare services and policy regarding telemedicine care deregulation [33].

\section{Future Research Direction}

The physical, digital and biological components of 4IR technology are creating a robotic socioeconomic ecosystem in the long term because of the redefinition of business models and much more. Future research directions should generally focus on improving privacy and data protection, the sustainability and management of digital technologies and the standardization of contactless services. Concerning the pace of digitization, protecting the use of personal information should be the topmost priority, thus calling for sweeping data privacy legislation to regulate tech companies that champion the use of these 4IR 
technologies within different sectors of an economy. Such regulation is necessary because of the fact that some of the digital systems developed in the midst of the pandemic were either not internationally standardised or accredited [9]. Generally, it is important to leverage 4IR technologies to help create a digital village concept, the rapid use of blockchain technology to improve the supply chain of goods and products and the rapid deployment of drone technology in agriculture and manufacturing. In addition, there are some gains in terms of mobile technology platforms for mobile payment, e-learning platforms and the boom in e-commerce. When these gains are not well managed and sustained, it could be eroded. Thus, if countries can bridge infrastructure and education gaps, it can continue leveraging $4 \mathrm{IR}$, both as an enabler for the COVID-19 recovery and as the foundation for a successful and inclusive future [8].

The sustenance of the digital world needs governments and institutions to work together to promote policies that continue to foster digital innovation and learning [36]. Thus, government should support the practical training of professionals in job-related re-skilling and up-skilling programs, the practical education and training of children and young people in new technologies who can be ready for the labour market and programs to encourage lifelong learning for the elderly to adequately adapt to the new technologies that were introduced during the COVID-19 pandemic [69].

Given that the pace 4IR with which technologies have accelerated during the COVID-19 pandemic, digital maturity models should be defined to help manage any gains recorded during this era. Such digital maturity models should include novice, followers, innovators and champions [68]. This is because the COVID-19 pandemic took the world by surprise, where persons who both are and are not technologically savvy had to use digital tools for most activities. In addition, technology innovators and businesses helped create these technologies for addressing physical distancing and many more platforms that encourage remote interactions.

Investment in digital technologies would increase throughput, increase efficiency, lower costs of digital transactions and improve the health and safety of workers. Digitization has impacted economic growth through inclusive finance, enabling the unbanked to migrate to formal digital payments and savings technology platforms [70]. Businesses have to rethink their business models to impact society and other sectors. The digitisation agendas of these sectors should be backed by their organizational culture to keep up with the times. Thus, without the right leadership and clear vision for the digital future, the gains would be difficult to sustain and manage.

The lessons learned during the COVID-19 pandemic waves and 4IR technology interventions can be applied to the future outbreaks. For instance, the outbreak of the Marburg virus in February 2021 in Guinea, West Africa. Though the Marburg virus has not been declared as a pandemic, the lessons learned from the use of 4IR technologies can be applied to avoid much infection spread worldwide.

In furtherance to the foregoing, this review has shown the increasing reliance by organisations, situated across a multiplicity of sectors, on these 4IR technologies in tackling operational challenges posed by the pandemic. It is implied that the continued deployment of these technologies will remain central to the strategic objective of such organisations whilst forming an integral part of any containment policies formulated and implemented at national and sub-national levels of government. However, the deployment of these technologies in situations such as is currently being experienced are not without shortcomings, as highlighted in Table 1. Therefore, it is expected that the findings from this review regarding these shortcomings will be considered by the leadership of such organisations and governments in the development of policies or strategies towards engendering more beneficial deployment of these technologies towards minimizing the impact of subsequent pandemic waves. 


\section{Conclusions}

In this paper, we reviewed the use of 4IR technology to tackle the COVID-19 pandemic waves. Among the 4IR technologies include artificial intelligence, big data, blockchain, cloud computing, IoT, 3D printing and robotics. We found that the COVID-19 pandemic has greatly accelerated research on the integration of digital technologies in healthcare, businesses, society, manufacturing and agriculture. These technologies have been applied to tackle the issues of contact tracing, social distancing, hotspot detection of the outbreak, supply chain and value addition, contactless services and many more. However, the issues of governments in creating the enabling network infrastructure that encourages farming digitization worldwide remain a challenge.

In respect of multi-sectors, the education sector has kept pace with digitization where students learn using online platforms thus encouraging social distancing and self-learning. The business sector experienced a boom in the use of digital platform for mobile money payment, increased migration of the unbanked to formal digital payment platforms, a boom in e-commerce and the redesign of the traditional face-to-face business service delivery. Social interaction and movement have been facilitated with the introduction of digital travel certificates, health status checkers, contact tracing platforms and the use of robots for disinfection tasks in the public space. The manufacturing sector has seen the use of blockchain technology to improve supply chain and the use of robots to perform some human related tasks. Agriculture has seen the use of drone technology for the surveillance and spraying of crops, the digitization of smallholder farms and the creation of digital villages. The mining sector saw the use of smart devices, including smart boot to prevent infectious viruses and smart health bands. The health sector witnessed the use of $4 \mathrm{IR}$ technologies including the use of robots for disinfection tasks and the use of telemedicine, thermal sensors, biosensors and much more.

Countries stand the chance to benefit immensely from the digitization to reform and empower the poor with access to information, more job opportunities, business-to-business growth in agro-processing and an increase in the usage of technology-based banking services. The IoT, AI and blockchain technologies can enhance data gathering and analysis for a targeted poverty reduction campaign. Moreover, 4IR technologies could help build a sustainable healthcare system and encourage the use of mobile technology to improve data collection, medical supply delivery and other healthcare service delivery. It could upskill the healthcare workers to offer improved services to patients. It is imperative to prioritise labour issues, 4IR integration into the global value chains, sweeping personal data privacy laws for tech industries and developing the physical and digital infrastructure of key sectors of a country. Open issues regarding digital platforms include personal data protection on a digital platform, data analysis poverty, how to sustain the gains made through government support programs, investment in drone technology in farming and the delivery of medical supplies.

Author Contributions: Conceptualization, writing—original draft preparation, I.E.A.; writingreview and editing, B.O.A.; conceptualization, writing-review and editing, A.B.N. All authors have read and agreed to the published version of the manuscript.

Funding: This research received no external funding.

Institutional Review Board Statement: Not Applicable.

Informed Consent Statement: Not Applicable.

Data Availability Statement: The study did not report any data.

Conflicts of Interest: The authors declare that they have no conflict of interest. 


\section{References}

1. Dutta, P.K. What Is a COVID-19 Wave? How Do We Identify It? Available online: https://www.indiatoday.in/coronavirusoutbreak/story/what-is-a-covid19-wave-how-do-we-identify-it-1800810-2021-05-10 (accessed on 10 May 2021).

2. Iftimie, S.; López-Azcona, A.D.; Vallverdú, I.; Hernández-Flix, S.; de Febrer, G.; Parra, S.; Hernández-Aguilera, A.; Riu, F.; Joven, F.; Andreychuk, N.; et al. First and second waves of coronavirus disease-19: A comparative study in hospitalized patients in Reus, Spain. PLoS ONE 2021, 16, e0248029. [CrossRef] [PubMed]

3. World Health Organization. There Is a Current Outbreak of Coronavirus (COVID-19) Disease. 2021. Available online: https: //www.who.int/health-topics/coronavirus\#tab=tab_1 (accessed on 4 August 2021).

4. Health Desk. What Are First, Second and Third Waves of Infections? 2021. Available online: https://health-desk.org/articles/ what-are-first-second-and-third-waves-of-infections (accessed on 7 June 2021).

5. Graichen, H. What is the difference between the first and the second/third wave of Covid-19?-German perspective. J. Orthop. 2021, 24. [CrossRef] [PubMed]

6. Results for Development. Implications of the Fourth Industrial Revolution for the Development Agenda in the Indo-Pacific Region; Results for Development: Washington, DC, USA, 2020; p. 32.

7. Khan, M.F.; Kaiser, K.; Morisset, J. Confronting COVID-19 Second Waves: How "Big Data for Good" Can Inform Policy in Vietnam. 2020. Available online: https://blogs.worldbank.org/eastasiapacific/confronting-covid-19-second-waves-how-bigdata-good-can-inform-policy-vietnam (accessed on 9 July 2020).

8. Oxford Business Group. The Fourth Industrial Revolution in Sub-Saharan Africa: Key to the Coronavirus Recovery? 2021. Available online: https:/ / oxfordbusinessgroup.com/news/fourth-industrial-revolution-sub-saharan-africa-key-coronavirusrecovery (accessed on 6 May 2021).

9. Ibrahim, M. The Fourth Industrial Revolution Combatting COVID-19: The Role of Smart and Sustainable Cities; United Nations Department of Economic and Social Affairs: New York, NY, USA, 2020; p. 6.

10. Rodríguez, I.; Rodríguez, J.V.; Shirvanizadeh, N.; Ortiz, A.; Pardo-Quiles, D.J. Applications of Artificial Intelligence, Machine Learning, Big Data and the Internet of Things to the COVID-19 Pandemic: A Scientometric Review Using Text Mining. Int. J. Environ. Res. Public Health 2021, 18, 8578. [CrossRef] [PubMed]

11. He, S.; Yang, J.; He, M.; Yan, D.; Tang, S.; Rong, L. The risk of future waves of COVID-19: Modeling and data analysis. Math. Biosci. Eng. 2021, 18, 5409-5426. [CrossRef]

12. Coccia, M. The impact of first and second wave of the COVID-19 pandemic in society: Comparative analysis to support control measures to cope with negative effects of future infectious diseases. Environ. Res. 2021, 197, 111099. [CrossRef]

13. Contou, D.; Fraissé, M.; Pajot, O.; Tirolien, J.A.; Mentec, H.; Plantefève, G. Comparison between first and second wave among critically ill COVID-19 patients admitted to a French ICU: No prognostic improvement during the second wave? Crit. Care 2021, 25, 1-4. [CrossRef]

14. Bontempi, E.; Vergalli, S.; Squazzoni, F. Understanding COVID-19 diffusion requires an interdisciplinary, multi-dimensional approach. Environ. Res. 2020, 188, 109814. [CrossRef]

15. Neto, R.d.C.S.; Maia, J.S.; de Silva Neiva, S.; Scalia, M.D.; de Andrade, J.B.S.O. The fourth industrial revolution and the coronavirus: A new era catalyzed by a virus. Res. Glob. 2020, 2, 7.

16. Sima, V.; Gheorghe, I.G.; Subić, J.; Nancu, D. Influences of the Industry 4.0 Revolution on the Human Capital Development and Consumer Behavior: A Systematic Review. Sustainability 2020, 12, 4035. [CrossRef]

17. Alsunaidi, S.J.; Almuhaideb, A.M.; Ibrahim, N.M.; Shaikh, F.S.; Alqudaihi, K.S.; Alhaidari, F.A.; Khan, I.U.; Aslam, N.; Alshahrani, M.S. Applications of Big Data Analytics to Control COVID-19 Pandemic. Sensors 2021, 21, 1-24. [CrossRef]

18. OECD. Cloud Computing: The Concept, Impacts and the Role of Government Policy. In OECD Digital Economy Papers; OECD Publishing: Paris, France, 2014; pp. 1-35.

19. HealthNewToday. Coronavirus May Spread Faster than WHO Estimate. 2020. Available online: https://www.medicalnewstoday. com/articles/coronavirus-may-spread-faster-than-who-estimate (accessed on 4 August 2021).

20. Foote, K.D. A Brief History of Cloud Computing. 2017. Available online: https://www.dataversity.net/brief-history-cloudcomputing/ (accessed on 4 August 2021).

21. Mahler, T.; Weber, M. Mobile Device Interaction in Ubiquitous Computing. In Advances in Human Computer Interaction; IntechOpen: London, UK, 2008.

22. ORock Technologies. A Practical Guide to Mission-Critical Cloud Computing; ORock Technologies: Reston, VA, USA, $2021 ;$ pp. 1-13.

23. Torre-Bastida, A.I.; Díaz-de-Arcaya, J.; Osaba, E.; Muhammad, K.; Camacho, D.; Del Ser, J. Bio-inspired computation for big data fusion, storage, processing, learning and visualization: State of the art and future directions. Neural Comput. Appl. 2021, 1-31. [CrossRef]

24. Javaid, M.; Haleem, A.; Vaishya, R.; Bahl, S.; Suman, R.; Vaish, A. Industry 4.0 technologies and their applications in fighting COVID-19 pandemic. Diabetes Metab. Syndr. Clin. Res. Rev. 2020, 14, 419-422. [CrossRef]

25. Zhang, P.; White, J.; Schmidt, D.C.; Lenz, G. Applying Software Patterns to Address Interoperability in BlockchainbasedHealthcare Apps. In Proceedings of the 24th Pattern Languages of Programming Conference, Vancouver, BC, Canada, 22-25 October 2017. 
26. IBM Global Business Services Public Sector Team. Blockchain: The Chain of Trust and Its Potential to Transform Healthcare-Our Point of View. In Proceedings of the ONC/NIST Use of Blockchain for Healthcare and Research Workshop, Gaithersburg, MD, USA, 8 August 2016.

27. Wang, Q.; Su, M.; Zhang, M.; Li, R. Integrating Digital Technologies and Public Health to Fight Covid-19 Pandemic: Key Technologies, Applications, Challenges and Outlook of Digital Healthcare. Int. J. Environ. Res. Public Health 2021, $18,6053$. [CrossRef]

28. Agbehadji, I.E.; Awuzie, B.O.; Ngowi, A.B.; Millham, R.C. Review of Big Data Analytics, Artificial Intelligence and Natureinspired Computing Models towards Accurate Detection of COVID-19 Pandemic Cases and Contact Tracing. Int. J. Environ. Res. Public Health 2020, 17, 1-13. [CrossRef]

29. Langthaler, M.; Bazafkan, H. Digitalization, Education and Skills Development in the Global South: An Assessment of the Debate with a Focus on SubSaharan Africa; ÖFSE Briefing Paper, No. 28; Austrian Foundation for Development Research (ÖFSE): Vienna, Austria, 2020.

30. Khomo, F.L.; Abayomi, A.; Adetiba, E.; Agbehadji, I.E.; Mutanga, B.M.; Jugoo, V. Digital Innovations for Post-CoViD-19 Pandemic Recovery. In Proceedings of the 2021 International Conference on Artificial Intelligence, Big Data, Computing and Data Communication Systems, Durban, South Africa, 5-6 August 2021; p. 7.

31. Miller, P. COVID-19 Fast-Tracking the Fourth Industrial Revolution. 2021. Available online: https://www.cipla.co.za/pressreleases/covid-19-fast-tracking-the-fourth-industrial-revolution (accessed on 6 May 2021).

32. Villegas-Ch, W.; Palacios-Pacheco, X.; Luján-Mora, S. Application of a Smart City Model to a Traditional University Campus with a Big Data Architecture: A Sustainable Smart Campus. Sustainability 2019, 11, 1-28. [CrossRef]

33. Lee, S.M.; Lee, D. Opportunities and challenges for contactless healthcare services in the post-COVID-19 Era. Technol. Forecast. Soc. Chang. 2021, 167, 120712. [CrossRef]

34. Chu, D.K.; Akl, E.A.; Duda, S.; Solo, K.; Yaacoub, S.; Schünemann, H.J.; El-Haraheh, A.; Bognanni, A.; Lotfi, T.; Loeb, M.; et al. Physical distancing, face masks, and eye protection to prevent person-to-person transmission of SARS-CoV-2 and COVID-19: A systematic review and meta-analysis. Lancet 2020, 395, 1973-1987. [CrossRef]

35. Rubega, G.F. How COVID-19 Accelerated Manufacturing into the 4IR. 2021. Available online: https:/ / www.wolfandco.com/ resources/insights/how-covid-19-accelerated-manufacturing-into-the-4ir/ (accessed on 4 August 2021).

36. Al-Ulyan, Y. Rebuilding after COVID: The Challenge Is Digital. 2021. Available online: https://www.weforum.org/agenda/2021 /06/rebuilding-the-world-after-covid-the-challenge-is-digital/ (accessed on 10 June 2021).

37. Zeng, Z.; Chen, P.; Lew, A. From high-touch to high-tech: COVID-19 drives robotics adoption. Tour. Geogr. 2020, $22,1-11$. [CrossRef]

38. Lee, S.M.; Lee, D. Untact': A new customer service strategy in the digital age. Serv. Bus. 2020, 14, 1-22. [CrossRef]

39. World Health Organization. Digital Documentation of COVID-19 Certificates: Vaccination Status. In Technical Specifications and Implementation Guidance; World Health Organization: Geneva, Switzerland, 2021; p. 99.

40. European Parliament. EU Covid-19 Certificate: A tool to Help Restore the Free Movement of People Across the European Union; European Parliament: Brussels, Belgium, 2021; p. 12.

41. European Commission. EU Digital COVID Certificate; European Commission: Brussels, Belgium, $2021 ;$ p. 3.

42. Schengenvisainfo News. All Details on EU COVID-19 Vaccine Passport Revealed: Here's What You Need to Know. 2021. Available online: https:/ / www.schengenvisainfo.com/news/all-details-on-eu-covid-19-passport-revealed-heres-what-youneed-to-know/ (accessed on 2 July 2021).

43. Elflein, J. COVID-19 Vaccine Doses Administered Worldwide as of August 2021, by Country. Available online: https:/ / www.statista. com/statistics/1194934/number-of-covid-vaccine-doses-administered-by-county-worldwide/ (accessed on 30 August 2021).

44. World Health Organization. Assessment of the COVID-19 Supply Chain System: Full Report. 2021. Available online: https: //www.who.int/publications/m/item/assessment-of-the-covid-19-supply-chain-system-report (accessed on 30 April 2021).

45. Ahuja, A.S.; Reddy, V.P.; Marques, O. Artificial Intelligence and COVID-19: A Multidisciplinary Approach. Integr. Med. Res. 2020, 9. [CrossRef]

46. Sattari, N. Women driving women: Drivers of women-only taxis in the Islamic Republic of Iran. Women's Stud. Int. Forum 2020, 78, 102324. [CrossRef]

47. Devrim, I.; Bayram, N. Infection control practices in children during COVID-19 pandemic: Differences from adults. Am. J. Infect. Control. 2020, 48, 933-939. [CrossRef] [PubMed]

48. Signé, L.; Khagram, S.; Goldstein, J. Using the Fourth Industrial Revolution to fight COVID-19 Around the World. 2020. Available online: https:/ / www.brookings.edu/techstream/using-the-fourth-industrial-revolution-to-fight-covid-19-around-the-world/ (accessed on 28 April 2020).

49. George, K. Manufacturing Reimagined: From Improved Productivity to Profitable Growth. 2021. Available online: https://www. weforum.org/agenda/2021/01/manufacturing-reimagined-from-improved-productivity-to-profitable-growth/ (accessed on 18 January 2021).

50. Barata, J.; Da Cunha, P.R.; Stal, J. Mobile supply chain management in the Industry 4.0 era. J. Enterp. Inf. Manag. 2018, $31,173-192$. [CrossRef]

51. MCA Connect. The Future of Manufacturing: Digital Acceleration, in New Trends and Innovations for the Industry; MCA Connect: Denver, CO, USA, 2021; pp. 1-14. 
52. Battle-Fisher, M. Transhuman, posthuman and complex humanness in the 21st century. Ethics Med. Public Health 2020, 13, 100400. [CrossRef]

53. Liu, Y.; Zhang, W.; Pan, S.; Li, Y.; Chen, Y. Analyzing the robotic behavior in a smart city with deep enforcement and imitation learning using IoRT. Comput. Commun. 2020, 2020, 346-356. [CrossRef]

54. Lamptey, E.; Serwaa, D. The use of Zipline drones technology for COVID-19 samples transportation in Ghana. HighTech Innov. J. 2020, 1, 67-71. [CrossRef]

55. Zhu, B.; Zheng, X.; Liu, H.; Li, J.; Wang, P. Analysis of spatiotemporal characteristics of big data on social media sentiment with COVID-19 epidemic topics. Chaos Solitons Fractals 2020, 140, 110123. [CrossRef]

56. Allam, Z.; Dey, G.; Jones, D.S. Artificial intelligence (AI) provided early detection of the coronavirus (COVID-19) in China and will influence future Urban health policy internationally. AI 2020, 1, 156-165. [CrossRef]

57. Shakhovska, N.; Fedushko, S.; Melnykova, N.; Shvorob, I.; Syerov, Y. Big Data analysis in development of personalized medical system. Procedia Comput. Sci. 2019, 160, 229-234. [CrossRef]

58. People's Daily Online. In This Way, Close Contacts Are Detected. Available online: http://paper.people.com.cn/rmrb/html/20 20-02/14/nw.D110000renmrb_20200214_1-12.htm (accessed on 4 August 2021).

59. Ahmed, N.; Michelin, R.A.; Xue, W.; Ruj, S.; Malaney, R.; Kanhere, S.S.; Seneviratne, A.; Hu, W.; Janicke, H.; Jha, S. A Survey of COVID-19 Contact Tracing Apps. IEEE Access 2020, 8, 134577-134601. [CrossRef]

60. Vidakis, N.; Petousis, M.; Velidakis, E.; Tzounis, L. The Response of the Hellenic 3D-Printing Community over the COVID-19 Pandemics: The Success Story of the Hellenic Mediterranean University. Am. J. Biomed. Sci. Res. 2020, 9, $199-203$.

61. Pappas, G.; Vidakis, N.; Petousis, M. Technology Driven Mitigation of COVID-19 Infection Risk in Retinal Surgery, by means of 3D Visualization Systems. J. Ophthalmol. Res. 2020, 3, 65-70. [CrossRef]

62. Nageshwaran, G.; Harris, R.C.; Guerche-Seblain, C.E. Review of the role of big data and digital technologies in controlling COVID-19 in Asia: Public health interest vs. privacy. Digit. Health 2021, 7, 1-12.

63. Atif, I.; Cawood, F.T.; Mahboob, M.A. The Role of Digital Technologies that Could Be Applied for Prescreening in the Mining Industry During the COVID-19 Pandemic. Trans. Indian Natl. Acad. Eng. 2020, 5, 663-674. [CrossRef]

64. Marin, A. Telemedicine Takes Center Stage in the Era of COVID-19. Science 2020, 370, 731-733. [CrossRef]

65. Wenyan, W.M. AI Strawberries and Blockchain Chicken: How Digital Agriculture Could Rescue Global Food Security. 2021. Available online: https://www.weforum.org/agenda/2021/01/china-digital-agriculture-global-food-security/ (accessed on 26 January 2021).

66. Fox, L.; Signé, L. The Fourth Industrial Revolution (4IR) and the Future of Work: Could this Bring Good Jobs to Africa? Evidence Synthesis Paper Series; INCLUDE Knowledge Platform: Leiden, The Netherlands, 2021; Volume 6, p. 51.

67. Mining Review Africa. Ten Insights Into 4IR—the State of Digital Transformation. 2021. Available online: https://www. miningreview.com/gold/ten-insights-into-4ir-digital-transformation-in-the-mining-industry/ (accessed on 18 May 2021).

68. Temkin, S. Ten Insights Into 4IR-The State of Digital Transformation in the South African Mining Industry; PwC and Minerals Council of South AFrica Report. 2021. Available online: https://www.pwc.co.za/en/press-room/10-insights-into-4ir.html (accessed on 4 August 2021).

69. Zervoudi, E.K. Fourth Industrial Revolution: Opportunities, Challenges, and Proposed Policies. In Industrial Robotics-New Paradigm; IntechOpen: London, UK, 2020; p. 26.

70. Ndung'u, N.; Signé, L. The Fourth Industrial Revolution and Digitization Will Transform Africa into a Global Powerhouse. 2020. Available online: https: / / www.brookings.edu/research/the-fourth-industrial-revolution-and-digitization-will-transform-africainto-a-global-powerhouse/ (accessed on 4 August 2021). 